Revista Cógnito v.2:2 (2020) 359 - 379

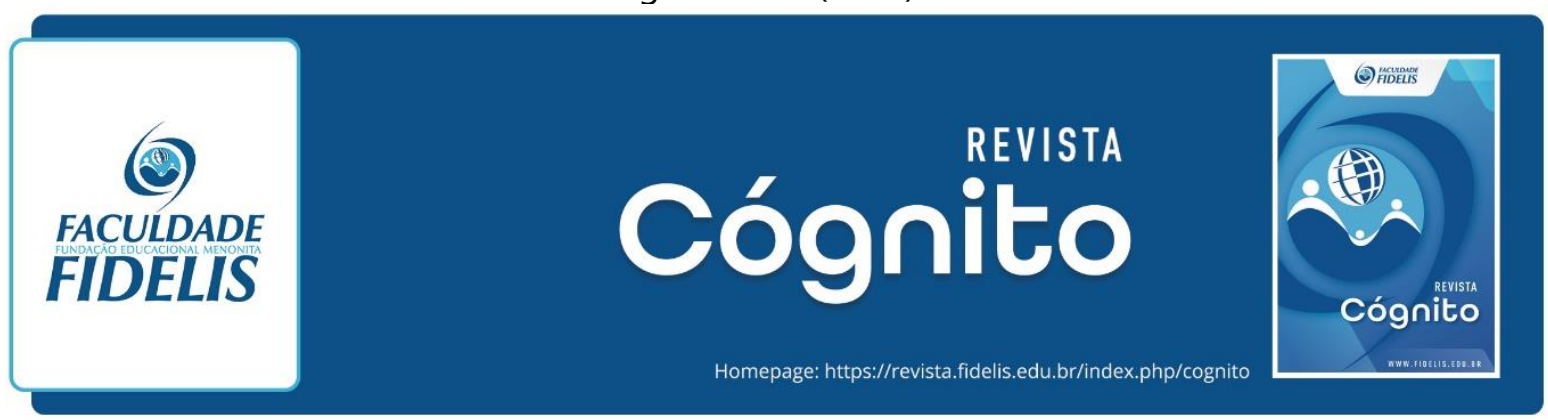

\title{
OS DESIGREJADOS NA COLÔNIA WITMARSUM
}

DIE GEMEINDELOSEN IN COLÔNIA WITMARSUM

\author{
Siegfried Pauls ${ }^{1}$ \\ Arthur Wesley Dück ${ }^{2}$
}

\begin{abstract}
RESUMO
O objetivo deste artigo é apresentar formas de aproximação da igreja para com os desigrejados da Colônia Witmarsum. Para isso utiliza-se a metodologia de pesquisa qualitativa, recorrendose antes, na parte teórica, ao auxílio de autores como Bomilcar (2012) e Burke (2006). As áreas trabalhadas na pesquisa de campo, definidas após uma entrevista com um líder da comunidade local foram: (1) Finanças; (2) Exclusão Social; (3) Testemunho Pessoal; e (4) Competição. Constatou-se que uma das principais razões para o afastamento de pessoas da instituição eclesiástica é o desapontamento daquelas para com esta. Sabendo disso, propõe-se que haja um equilíbrio entre ambas as partes: por parte dos desigrejados, o reconhecimento de que a igreja é formada por pessoas falhas; por parte da igreja, o compromisso de ser exemplar em sua conduta.
\end{abstract}

Palavras chave: Desigrejados; Colônia Witmarsum; Igreja;

\section{ZUSAMMENFASSUNG:}

Diese Abschlussarbeit hat das Ziel, Annäherungsmöglichkeiten zwischen den Gemeinden in Witmarsum und den Gemeindelosen dort aufzuzeigen. Dazu wurden zunächst private Interviews mit dieser Personengruppe durchgeführt, die sich auf vier Hauptbereiche beziehen:(1) Finanzen (Habsucht); (2) soziale Ausgrenzung; (3) Persönlicher Lebenswandel (Leben der Glieder während der Woche); und (4) Konkurrenzdenken (Konflikte/ Neid). Dem theoretischen Teil liegen Arbeiten von Bomilcar (2012) und Burke (2006) zugrunde. Einer der Hauptgründe für die Distanz zur Gemeinde ist die Enttäuschung über die Gemeinde als Institution. Das Wissen über die Ursachen dieser Distanzierung führte zu dem Vorschlag, dass doch beide Gruppen unter folgenden Bedingungen aufeinander zu gehen könnten: die Gemeindelosen müssen erkennen, dass die Gemeinde nicht aus fehlerlosen Menschen besteht und so Verletzungen wie auch Enttäuschungen vorprogrammiert sind. Andererseits haben die Gemeindeglieder die Aufgabe, einen vorbildhaften Lebenswandel zu führen.

Schlüsselworte: Gemeindelosen; Siedlung Witmarsum; Gemeinde;

\footnotetext{
${ }^{1}$ Bacharel em Teologia pela Faculdade Fidelis

${ }^{2}$ Doutor em Teologia pela Escola Superior de Teologia - EST. Docente do curso de Bacharelado em Teologia da Faculdade Fidelis. arthur.duck@fidelis.edu.br
} 


\section{INTRODUÇÃO}

Ouve-se falar muito sobre os desigrejados e suas dificuldades no contexto urbano, mas no contexto rural, em uma comunidade, na qual quase não há anonimato? Olhando para a realidade da Colônia Witmarsum, se constata um grande número de pessoas alheias ou afastadas, que por algum motivo se tornaram indiferentes em relação à igreja. Entre eles se encontram, por exemplo, cidadãos que no passado já participaram do grupo de jovens, frequentavam os cultos dominicais, mas hoje não tem nenhum interesse em fazer parte de atividades eclesiásticas. Vivem, em alguns casos, à margem da sociedade e também na "periferia espiritual" da colônia. Em meio a este contexto pretende-se descobrir o que se passa na mente destas pessoas.

Esse trabalho tem como propósito descobrir o que levou os desigrejados da Colônia Witmarsum a se frustrarem com a igreja e, a partir dessa constatação, apresentar formas de aproximação da igreja para com esse público. Para isso, primeiramente será definido o termo "desigrejado", em seguida apresentado brevemente a Colônia Witmarsum, para então relacionar ambos, através da exposição de dados da entrevista qualitativa. Por fim, sugerem-se alterações eclesiásticas que possam aproximar o público desigrejado da instituição.

Metodologicamente este artigo adotou o tipo de pesquisa bibliográfica e pesquisa de campo qualitativa. Autores como Burke (2006) e Bomilcar (2012) auxiliaram para a definição do termo desigrejados. Pauls (2010, 2011) e Cairns (2008) foram utilizados para apresentar breves conceitos sobre a Colônia Witmarsum e os menonitas. Através de entrevistas qualitativas, busca-se descobrir as razões que levaram os desigrejados da Colônia Witmarsum a se afastar da vida da Igreja e em segundo plano, com base na análise das entrevistas, pretendese dar uma proposta às lideranças desta comunidade, de como a Igreja neste contexto pode se tornar mais relevante. Este trabalho propõe servir de incentivo para as lideranças locais a encontrar um caminho para entender e se aproximar mais deste público - dos que não querem saber de Igreja - e ser mais relevante na sociedade.

O autor deste artigo escolheu o tema, motivado por algumas constatações pessoais: (1) que o número de pessoas "desigrejadas", que vivem alheias à vida ativa da igreja, vem aumentando na Colônia Witmarsum; (2) Líderes desta comunidade têm tido uma grande dificuldade em se aproximar deste público, como também aproximá-los da Instituição Igreja; (3) Nesta comunidade, as pessoas convivem em um ambiente muito próximo umas das outras. Com tal proximidade, quase não há privacidade, forçando assim que a pessoa carregue uma 
máscara para poder "sobreviver". É neste contexto que se pretende ir um pouco mais a fundo, para descobrir a razão de tanta dor, frustração e decepção dos desigrejados em Witmarsum.

\section{DEFINIÇÃO DOS DESIGREJADOS}

A igreja como instituição, como descreve Múzio, perdeu a credibilidade. Segundo ele “as pessoas não parecem estar levando a igreja a sério" (2010, p. 13). Silva (2007, p. 13) e Cole (2007, p. 16) notam que, no meio de pessoas que não têm uma relação contínua com a igreja, há um grande e crescente interesse pelo conhecimento de Cristo, porém uma grande aversão quando o assunto passa a ser igreja.

Mariz e Machado alertam para o fato de que pessoas sem interesse pela instituição eclesiástica "não podem e não devem ser confundidos com ateus ou descrentes da existência de Deus" (1998, p. 36). No mesmo raciocínio, Jacob esclarece que "uma parcela daqueles que se declaram sem religião, acreditam em Deus sem participar, no entanto, das instituições” (2003, p. 115).

É esse público que será denominado nesse trabalho de "desigrejados": pessoas que creem em Deus, mas consequente à perda de credibilidade da igreja, não participam da instituição eclesiástica. Segundo Bomilcar:

Eles crescem de forma avassaladora como uma nova tribo informal, por todos os cantos, muitos tendo caído ou desistido da igreja, seja ela de que expressão for, mas em especial aquelas reunidas em templos ou instituições eclesiásticas. (2012, p. 1516).

Dentro deste público desigrejado, percebe-se diferentes grupos. Bomilcar aponta que (1) há os "que se assumem sem-igreja, sem vínculos, parcerias ou compromissos com programações eclesiásticas"; (2) também "existem os que desanimaram com a instituição formal religiosa e mantêm uma distância preventiva moderada. Tornaram-se apenas frequentadores esporádicos, participando de projetos ou encontros com algum interesse" e, (3) tem aqueles "que se encontram em grupos pequenos informalmente em casas, salões alugados ou outros estabelecimentos" (BOMILCAR, 2012, p. 23).

Olhando para os desigrejados da comunidade de Witmarsum, percebe-se que a maioria dos entrevistados se encaixa na segunda categoria de Bomilcar. Ou seja, são pessoas que se decepcionaram com a igreja e com isso vivem mais como expectadores distanciados, participando esporadicamente de um evento ou de outro. 
Entre os principais motivos para o crescimento dos desigrejados estão os conflitos mal resolvidos e a falta de diálogo aberto (BOMILCAR, 2012, p. 155). Segundo César (2009, p. 15), a Igreja, um lugar onde as pessoas deveriam receber cura e "bálsamo" para as suas feridas, se torna um local, nos quais elas são feridas e se decepcionam.

Se, por um lado, percebe-se a culpa da igreja no crescimento numérico dos desigrejados, por outro lado, também é necessário reconhecer que a igreja é composta por pessoas mal resolvidas, doentes e machucadas que precisam de cura (Mt 9.12). Segundo Oliveira,

\begin{abstract}
Na cabeça de alguns, a vida cristã deveria acontecer em uma espécie de espiritosfera ou região sobrenatural, aquele ambiente esvaziado de nossa humanidade [...] é necessário colocar os pés no chão, e olhar a comunidade, o ser igreja, como o lugar de encontro no qual experimentamos ao mesmo tempo a riqueza das experiências relacionais saudáveis e as dores das tensões que existem onde pessoas se encontram (apud BOMILCAR 2012, p. 212)
\end{abstract}

Múzio, enxergando o crescimento numérico dos decepcionados com a igreja, alerta que "é altamente impossível que alguém encontre coerência na vida espiritual no labirinto da vida pós-moderna sem o envolvimento com uma igreja cristã” (MÚZIO, 2010, p. 43).

Percebe-se conforme Múzio, que apesar da deficiência da igreja, ela se faz necessária para que seus frequentadores possam "sobreviver" no âmbito espiritual, na qual se pode experimentar comunhão e crescimento. Viu-se assim que os desigrejados são pessoas desinteressadas em participarem da instituição eclesiástica. Essas pessoas não podem ser generalizadas como ateias, porque muitas querem conhecer a Cristo, mas não participar da igreja. Esse desinteresse pode ter sido causado por falta de resolução de conflitos, ou por falta de transparência por parte da igreja. Por outro lado, Múzio e Oliveira desafiam a enxergar a igreja com mais realismo e espiritualizar menos. Com essas constatações, quer se partir para a apresentação de algumas características da Colônia Witmarsum: sua origem e sua cultura.

\title{
2 A COLÔNIA WITMARSUM E OS MENONITAS
}

A Colônia Witmarsum, o local de pesquisa deste artigo, segundo Ferreira (1988, p. 104) foi organizada em 1951, inicialmente em campos pobres, impróprios para atividades agropecuárias, pelos Menonitas, quando estes se estabeleceram no município de Palmeira, Paraná. Pauls acrescenta que foram 60 famílias Menonitas, "remanescentes da antiga Colônia e atual Município de Witmarsum, em Santa Catarina” (2010, p. 155) que compraram, com suas poucas reservas e "com a ajuda de um empréstimo das igrejas Menonitas do Canadá", parte da 
Fazenda Cancela (2011, p. 231). Holm e Cardozo informam que a comunidade de Witmarsum é formada por aproximadamente 2000 pessoas, das quais, estima-se que 1200 pertençam a etnia de origem Menonita alemã e 800 não sejam Menonitas de berço (HOLM, CARDOZO, 2015, p. 7).

Os Menonitas são descendentes diretos dos anabatistas (SHELLEY, 2004, p. 275; CAIRNS, 2008, p. 274). A razão da relação entre os anabatistas e os Menonitas explica-se em Menno Simons (1496-1561) homem que, segundo Cairns, tinha aceitado as ideias anabatistas e abandonado seu sacerdócio na Igreja Romana em 1536. Assumiu, então, a liderança dos "irmãos", nome dado aos anabatistas da Holanda, que após a morte dele "passaram a ser conhecidos como Menonitas" (CAIRNS, 2008, p. 276).

McGrath expõe que "o termo 'anabatista' significa literalmente 'aquele que rebatiza'." Os anabatistas se opunham ao batismo infantil, tido por eles como antibíblico, e insistiam no rebatismo. Para McGrath é justamente essa persistência de que somente podiam ser batizados aqueles que haviam feito uma confissão pessoal e pública de fé que compõe, possivelmente, o aspecto mais distintivo da prática anabatista (MCGRATH, 2007, p. 181).

Shelley classifica o anabatismo como uma importante expressão da reforma protestante. Ele enxerga que esse movimento nasceu quando um jovem padre, chamado George Blaurock batizou os demais, após, por solicitação própria e com a confissão pessoal da fé em Jesus Cristo, ter sido batizado por Conrad Grebel (2004, p. 275). Pauls data esse evento para 21 de janeiro de 1525 e informa que Blaurock batizou Conrad Grebel e Feliz Manz (2010, p. 27 28). Segundo Cairns, após ter sido batizado por Grebel, Blaurock "batizou Grebel e vários outros" (CAIRNS, 2008, p. 274).

Com isso, pode-se afirmar que o anabatismo é um movimento de fé, surgido na época da reforma protestante, marcado pelo rebatismo. Todavia, "é difícil sistematizar as crenças anabatistas, porque houve muitos grupos anabatistas diferentes em suas doutrinas", e isso é devido à "convicção de que o crente tem o direito de interpretar a Bíblia como autoridade literal e final" (CAIRNS, 2008, p. 276). No entanto, o próprio Cairns e também McGrath observam alguns elementos em comum dentro de um movimento tão distinto:

O primeiro ponto comum destacado por Cairns é que os anabatistas veem a autoridade da Bíblia “como regra final e infalível de fé e prática”. Em seguida, abordando os participantes da Igreja, ele observa que os anabatistas creem "que a verdadeira Igreja era uma associação dos regenerados e não uma igreja oficial de que participavam até não-salvos". A maioria acentua “a completa separação entre Igreja e Estado", não mantendo "vínculos com as igrejas estatais". Cairns ainda destaca a prática do batismo dos crentes e o fato que "alguns pendiam ao 
pacifismo, negavam-se a fazer juramentos nos tribunais e a servir como magistrados" (CAIRNS, 2008, p. 277).

Já McGrath acentua como aspectos em comum do movimento anabatista: (1) a presença de "uma desconfiança geral das autoridades externas"; (2) "a rejeição do batismo de crianças em favor do batismo de cristãos adultos"; (3) "a posse comum das propriedades"; e (4) "uma ênfase sobre o pacifismo e não-resistência" (McGRATH, 2007, p. 181). Todavia, pertencer ao povo Menonita nem sempre significa coparticipação na fé:

Ser "menonita" deveria ser, antes de mais nada, uma característica de um grupo de fé, uma denominação cristã, uma definição de doutrina e prática, mas as circunstâncias contribuíram para que houvesse quase que uma sociedade, ou melhor, uma etnia que desenvolveu seus valores, seus princípios e sua forma de ser para agora ter características muito próprias (JANZEN, 2010, p. 118).

Com base no comentário de Janzen, acompanhada da definição histórica dos anabatistas feita por Cairns e McGrath, pode-se concluir que os Menonitas perderam, com o tempo, suas principais características associadas ao movimento de fé, e receberam a conotação de serem um grupo étnico. É esse povo, religioso, mas também étnico, que fundou a Colônia Witmarsum e continua representando a maioria da população desse local. Conhecendo um pouco da história, e do povo dessa comunidade, pretende-se então avançar para a apresentação de dados coletados na pesquisa.

\section{OS DESIGREJADOS NA COLÔNIA WITMARSUM}

A pesquisa de campo realizada foi qualitativa, sendo entrevistados 9 moradores da Colônia Witmarsum, que vivem mais à margem da sociedade, com idade entre 27 e 60 anos. Dessas 9 pessoas, 5 são agropecuaristas, 2 são comerciantes locais e 2 estão aposentados. A seleção dessas pessoas foi feita com base em dois critérios: (1) o autor deste artigo já tinha um relacionamento amigável com elas, facilitando com isso o desenvolvimento da pesquisa; (2) elas estão entre o grupo de pessoas que melhor caracterizam os desigrejados. As entrevistas foram individuais e pré-agendadas, conduzidas por perguntas semi-abertas e abertas, que visavam um diálogo mais aberto com o público-alvo.

Para fazer o levantamento das perguntas, foi realizada antes uma entrevista com um dos líderes da comunidade, membro de igreja, que conhece bem a realidade da Colônia Witmarsum, podendo assim fornecer um importante direcionamento para uma pesquisa mais eficaz. Com sua influência, a pesquisa com o público desigrejado abrangeu 4 áreas: (1) Finanças (ganância); (2) Exclusão social; (3) Testemunho pessoal (Igreja durante a semana); e (4) 
Competição (conflito e inveja). Para tal foram elaboradas diversas perguntas para orientar o pesquisador em suas entrevistas.

\subsection{FINANÇAS/GANÂNCIA}

Em uma comunidade pequena e étnica, a comparação entre pessoas é inevitável. No que tange à parte financeira, há pessoas que deslancharam financeiramente mais que as outras. Principalmente no âmbito financeiro há muita competição, o que tem gerado inveja, conflitos e outros problemas. Eduardo percebe que "há muita briga por motivos financeiros". Para Marcelo e João a ganância destrói relacionamentos. Sílvia comenta que "não existe mais união. Um passa a perna no outro!". João também observa que “um membro tapeia o outro" e complementa que “os cristãos não veem isso como mal”. Pode-se assim afirmar que os desigrejados destacam a presença de brigas e falsidade entre os membros da igreja no âmbito financeiro. Além disso, o egoísmo também é perceptível. João comenta que "cada um se arrasta sozinho". Para Eduardo, "há muita mesquinhez" entre os membros. Já Pedro classifica os membros em dois grupos: os generosos e os menos generosos. Porém, observa que "esse segundo grupo acha que tem mais poder durante a semana".

Referente à distinção de grupos, Pedro também observa que "grupos de pessoas com posse não se misturam com os que têm menos". Segundo João, "quem tem dinheiro, tem tudo. Quem tem dinheiro tem amigos". Marcelo, analisando o patamar dos produtores de leite, nota como os maiores absorvem os lotes à venda, dificultando a vida dos pequenos produtores. Pedro, em contrapartida, enxerga que a Cooperativa, liderada por membros da igreja, auxilia os mais pobres, dentro de suas capacidades. Porém, reconhece que ela poderia fazer mais, classificando como injusto o pagamento da produção de leite por quantidade [quanto maior o volume, maior o preço por litro], vendo que o mesmo tende a prejudicar os produtores menores.

No âmbito financeiro, conclui-se que os desigrejados da Colônia Witmarsum notam a presença de elitização, falsidade, contendas e egoísmo nos membros da igreja.

\subsection{EXCLUSÃO SOCIAL}

Acompanhando a elitização, observa-se também a forte presença da exclusão social na Colônia Witmarsum. Como a maioria se conhece muito bem, é comum pessoas ou familiares serem rotulados ou até excluídos, vivendo assim à margem da sociedade. É fato que algumas famílias são mais bem-vistas do que outras. André nota que "em Witmarsum tem muita 
discriminação. Existe o 'bode expiatório'. Todos apontam o dedo para ele”. Felipe relata que “em Witmarsum, quando o cara pisa na bola é excluído". Eduardo afirma que: “eu sou um que pisou na bola! Fui difamado. Sou separado".

Pedro, no entanto, crê que "tudo é recuperável. A pessoa que caiu em desgraça tem como se levantar de novo". O que ao seu parecer falta, em Witmarsum, "é conversar sobre conflitos" e também que a igreja esteja disposta a resolver conflitos, não se isentando da sua responsabilidade nesta área. Sobre a falta de conversas, Pedro cita um exemplo positivo, seu vizinho: "Gosto muito do meu vizinho [é pastor], que me convida e também me visita. Ele me convida para tomar cerveja com ele. Eu me sinto bem com ele”.

Além da exclusão social por erro e da falta de comunicação, também há a classificação por posição social. Felipe observa que o "status social, aqui dentro da Colônia, fala muito alto [...] O nome aqui dentro tem uma grande influência, tipo 'ele vem daquela família"'.

André, utilizando o exemplo de seu irmão, conta como ex-moradores da Colônia Witmarsum se deram bem financeiramente, emocionalmente e espiritualmente em outro lugar: "Tenho visto que pessoas que não se deram bem aqui dentro, se deram bem 'lá fora'. O cara muda para um outro lugar ou outro país e ele cresce."

Conforme os dados acima expostos, são identificados três razões que fortalecem a presença de exclusão social na Colônia Witmarsum: (1) pessoas que, de fato, falharam em alguns momentos da vida, e que consequentemente acabaram excluídas; (2) status social das pessoas; (3) falta de comunicação e consequente fuga da resolução de conflitos.

\subsection{TESTEMUNHO PESSOAL}

Com a exposição dos relatos acima já é perceptível como os frequentadores ou membros da Igreja são observados pelo público desigrejado. Compreende-se com isso, que o testemunho pessoal do público que frequenta a igreja é observado, seja positivo ou negativo.

Dos nove entrevistados que mencionaram algum desapontamento com o testemunho dos cristãos, cinco comentaram que o comportamento dos membros é um no domingo e outro durante a semana. Entre as práticas semanais desaprovadas, André cita o não pagamento de dívidas, Felipe aborda os conflitos, Marcelo apresenta maus-tratos dos patrões para com os empregados, Ricardo afirma que seus pais foram humilhados por cristãos e Sílvia condena a forma como é julgada. Constata-se, além da presença de feridas, também a decepção por parte do público desigrejado para com os membros da igreja. João afirma que "existem muitas pessoas feridas em Witmarsum. O que falta é conversa e visitação. As pessoas não são visitadas. 
A liderança não visita os feridos e os que não estão bem". Citando seu próprio exemplo, ele comenta que está “fora da igreja há 4 anos e não veio ninguém”. Eduardo observa que: "Há muita fofoca, um rebaixa o outro. Quando eu olho para os cristãos e membros de igreja aqui em Witmarsum, eu percebo que há pessoas tristes, amarguradas, ofendidas [...]. Eu vejo poucas pessoas realmente felizes. Como seria bom, se as pessoas aqui em Witmarsum pudessem desabafar com alguém."

Felipe conta que "os jovens [da igreja] condenam. Tem membros que conversam comigo e outros me evitam. Os mais velhos é que vem conversar comigo." Quando perguntado sobre a influência da igreja na colônia, Felipe indagou: "Não se misturam”.

Se de um lado foram notadas as feridas provocadas pelo mau testemunho dos membros da igreja, por outro, se faz necessário reconhecer que também houve menção de exemplos positivos. Sílvia relata que ela e o marido passavam por momentos difíceis no seu comércio, com a saída de um sócio, quando foram auxiliados por um vizinho cristão, que tinha câncer: “ele foi um conselheiro nosso. Sentávamos nos fundos do nosso comércio e conversávamos. Até choramos juntos". Ela menciona que quando esse conselheiro já estava desenganado pelos médicos, chegou a eles e disse: "Quero comer pizza com vocês!”. Outro a relatar uma experiência positiva é o André. Ele diz que teve uma boa conversa com seu amigo cristão, num piquenique da igreja. Também comenta que os cristãos "têm assuntos que me interessam, como questões de plantio e agricultura em geral".

\subsection{COMPETIÇÃO E INVEJA}

Na comunidade de Witmarsum cada um sabe da vida e do passado do outro. Como os moradores de Witmarsum vivem muito próximos um do outro também há muita comparação que obviamente gera competição. O povo Menonita também se tornou conhecido como um grupo muito dedicado ao trabalho.

O que se ouve com frequência é a frase: “A pessoa que tenta abrir um próprio negócio em Witmarsum, não prospera!!” Pessoas, que abriram um negócio próprio, não eram bemvistos, ou sofreram até um certo "boicote", por motivo de inveja. Felipe concorda "que tem muita competição. Principalmente, quando se trata do preço do leite. Um produtor quer saber quanto o outro ganha pelo litro do leite vendido. Se um produtor compra uma máquina nova o outro também compra".

Numa comunidade como Witmarsum logo se percebe quem é mais abastado. João confirma: "Um não quer que o outro se dê bem naquilo que ele faz." Para Marcelo, "quem mora 
em Witmarsum tem uma mentalidade mais fechada. Quando sai, a sua mente se abre". Ele observa que "Os holandeses (Carambeí e Castro) também brigam, mas na hora de ganhar dinheiro, eles se juntam (união). Esta é uma das diferenças em relação a Witmarsum. Aqui na colônia cada um quer ganhar sozinho!"

Percebe-se como ao longo dos anos se perdeu a união que havia nos primórdios da Colônia Witmarsum. O interesse coletivo e a ajuda mútua deram lugar ao individualismo, à competição e consequentemente a inveja destrói os relacionamentos. Esses valores, contrários aos ensinos da Bíblia não deveriam caracterizar as pessoas que procuram seguir os ensinamentos de Jesus. Todavia os desigrejados veem justamente essas características nas pessoas que frequentam a igreja.

\section{UMA IGREJA PARA OS DESIGREJADOS NA COMUNIDADE DE WITMARSUM}

Ao olhar para os "desigrejados" na Colônia Witmarsum, percebe-se que para muitos a Igreja se tornou um corpo estranho, algo desconhecido, distante, paradoxal e supérfluo. Percebeu-se que os elementos pesquisados no tópico anterior causam frustrações, medo e distanciamento entre os moradores desta comunidade. Diante do clamor dos desigrejados de Witmarsum, torna-se necessária uma igreja relevante.

Antes disso, porém, é necessário entender o que significa "ser igreja". O termo igreja, na forma grega ekklêsia, segundo O'Brien, aparece 114 vezes no Novo Testamento, sendo que "nos ambientes grego e judaico antes e na época do NT [...] significava uma assembleia ou reunião de pessoas" (O’BRIEN, 2012, p. 640).

Marshall, ao apresentar o desenvolvimento do tema igreja nos Evangelhos, recorda que "os quatro Evangelhos foram produzidos em comunidades cristãs por pessoas que acreditavam que a existência desses grupos era a consequência natural da vinda de Jesus". Ele também informa que nos Evangelhos “a palavra 'igreja' propriamente dita é encontrada em Mateus 16.18 e 18.17", sendo essas "as duas únicas ocorrências do termo nos quatro Evangelhos" (MARSHALL, 2012, p. 635).

Carson afirma que nessas passagens "não há ênfase na instituição, na organização, na forma de adoração nem na sinagoga separada”. Retendo-se à passagem de Mateus 16.18, ele comenta que "Jesus, reconhecido como o Messias, responde que edificará sua ekklêsia, seu povo, sua igreja". A palavra "igreja" pertence ao conceito povo. "Jesus fala de seus seguidores como seu povo - sua igreja - que alcança o momento de se ver como o povo da nova aliança estabelecida pelo sangue do Messias." (CARSON, 2010, p. 433). 
Todo esse material mostra que Jesus proclamou o governo de Deus e conclamou o povo a voltar para Deus em atitude de arrependimento e obediência; que ele os chamou para ser seus discípulos e constituir a ekklêsia do Messias; que ele os via como filhos de Deus chamados a viver unidos como irmãos. Pode se afirmar com segurança que temos aqui a essência da igreja (MARSHALL, 2012, p. 638).

Nas cartas paulinas, a expressão ekklêsia aparece 62 vezes, sendo que Paulo atribui a essa palavra os seguintes significados: (1) Uma assembleia local ou congregação de cristãos; (2) uma igreja reunida numa casa; (3) uma reunião celestial (O'BRIEN, 2012, p. 640-642). Ao relacionar esses diferentes usos que Paulo faz de ekklêsia, O'Brien sugere que "as reuniões locais, numa congregação ou numa igreja doméstica, eram manifestações terrestres da reunião celeste em torno do Cristo ressuscitado" (O'BRIEN, 2012, p. 642). Para ele, o ato de reunir "é um elemento essencial da ekklêsia" (O'BRIEN, 2012, p. 645) e tem como propósito (1) a edificação e (2) o encontro com Cristo.

(1) 'O termo 'edificação', que se refere ao crescimento e ao progresso dos crentes, não deve ser interpretado de forma individualista. No ensino do apóstolo sobre a edificação existe tanto a dimensão corporativa quanto a pessoal" (O'BRIEN, 2012, p. 646).

(2) Uma forma importante de expressar o relacionamento com Jesus era reunir-se na congregação. “A reunião cristã autêntica não é apenas uma expressão da igreja celeste que no presente se reúne em torno de Cristo nos céus: é também uma antecipação dessa bendita consumação" (O'BRIEN, 2012, p. 647).

Utilizando as contribuições dos autores acima citados, pode-se afirmar que, com base nos Evangelhos e nas cartas paulinas, ser igreja é pertencer ao povo de Cristo. Este povo é um grupo de pessoas que, em atitude de arrependimento e obediência, voltou para Deus, sendo visto por Cristo como filhos de Deus e chamado por ele a viver unido como irmãos. Um elemento essencial desse grupo são suas reuniões que tem como propósito a edificação e o encontro com Cristo.

Recorrendo ao texto de Lucas 4.18,19, podemos ter uma ideia, de como é uma igreja que se reúne em torno da pessoa de Jesus. O texto de Lucas descreve a missão de Jesus nesta terra e o que era prioridade para Ele e o que deve ser prioridade para a igreja também. Percebese que Jesus vislumbrava o ser humano holisticamente, isto é, enxergando-o integralmente, como um todo, corpo, alma e espírito, "pregando, curando e suprindo todas as necessidades humanas" (BARKER, 2003, p. 1732). A entidade eclesiástica é desafiada a avistar o ser humano em sua totalidade. Como um ser que tem necessidades físicas, emocionais e espirituais.

“[...] para pregar boas novas aos pobres" (Lc 4.18). O termo pobres, neste caso, não se refere primeiramente à pobreza material, mas à pobreza de ordem espiritual. Como nota Stott: 
“Assim, ser `humilde (pobre) de espírito`é reconhecer a nossa falência espiritual diante de Deus, pois somos pecadores [...] e nada merecemos além do juízo de Deus. Essa atitude protege do orgulho espiritual e torna a pessoa acessível e mais humilde. Stott continua: "Nosso lugar é ao lado do publicano da parábola de Jesus, clamando com os olhos baixos: 'Deus, tem misericórdia de mim, pecador!'”(STOTT, 1978, p. 28-29).

“[...] para proclamar liberdade aos presos" (Lc 4.18). O texto não fala de cativeiros visíveis, físicos e sim de cativeiros morais e espirituais como confirma Champlin“. O cativeiro referido nestes versículos pode ser reputado como um cativeiro moral e espiritual." (CHAMPLIN, 2002, v. 2, p. 50)

Existem inúmeras “prisões”. Seres humanos presos em suas frustrações, seus erros e pecados como nota Champlin "Prisões tem existido [...] e nas Escrituras o pecado é pintado como o pior de todos os carcereiros" (CHAMPLIN, 2002, v. 2, p. 50). Cabe à igreja por intermédio de Jesus cuidar, amparar, curar e libertar os oprimidos (Lc 4.18). Como comenta Cole "Onde Jesus está trabalhando em nosso meio? Onde vemos vidas e comunidades transformadas simplesmente pelo poder do evangelho?” (COLE, 2005, p. 83). A igreja de Witmarsum, seguindo os passos de Jesus precisa se conscientizar que apesar de muitas coisas boas que faz, também está deixando diversas pessoas machucadas à margem da estrada.

Conhecendo a essência e o propósito da igreja, entrar-se-á agora na questão da relevância da mesma, em relação aos desigrejados da Colônia Witmarsum.

\subsection{CRIANDO UMA CULTURA CRISTOCÊNTRICA}

A primeira proposta para ser uma igreja mais relevante em Witmarsum é focar mais em Cristo e menos na instituição eclesiástica. No tópico 1, viu-se que entre os desigrejados há um número crescente de pessoas que tem interesse em conhecer mais a Jesus. Também foi abordado anteriormente que um dos propósitos das reuniões eclesiásticas, citadas nas cartas paulinas, é o encontro com Jesus.

Kivitz afirma que "nada pode ocupar nosso desejo mais do que o Cristo crucificado e ressurreto [...] jamais podemos perder Jesus de vista" (KIVITZ, 2006, p. 89). Kimball alerta que o objetivo do cristão "não deve ser o de levar as pessoas para a igreja [...] o objetivo é ver o Espírito de Deus transformar as pessoas em discípulos de Jesus, independentemente se elas frequentam ou não o culto todo domingo.” (KIMBALL, 2011, p. 217). Perdue porém nota que "nas igrejas de hoje é fácil ouvir o convite a entrar num sistema de crença, em lugar de relacionamento" (PERDUE, 2009, p. 31). 
A demasiada ênfase na instituição eclesiástica foi o descontentamento de um dos entrevistados: "Por que insistir tanto na instituição igreja?". Junto a isso, surgiu a proposta de focar mais na pessoa de Jesus. Jacobsen e Coleman, observando a forma como os primeiros cristãos se reuniam, compreendem que "a igreja simplesmente emerge das mais lindas formas" onde Jesus tem primazia (JACOBSEN, COLEMAN, 2009, p. 44, 131, 182). Perdue sugere às lideranças das igrejas que elas "deveriam se preocupar mais em levar os seus frequentadores ou ouvintes a uma Identidade positiva. Ou seja: Quem ela é aos olhos de Cristo?” (PERDUE, 2009, p. 38)

Os desigrejados da Colônia de Witmarsum querem Jesus. É com a instituição igreja que eles têm problemas. Kimball, em uma de suas entrevistas, cita como uma mulher "gostaria que a igreja ensinasse mais sobre Jesus". (KIMBALL, 2011, p. 230).

Cole afirma que sempre se está "fazendo a pergunta errada: Onde? O tempo todo, a questão certa é: Quem? Onde você adora não é nada em comparação a Quem você adora" (COLE, 2007, p. 67). Ele nota que na primeira vez que Jesus aborda o tema igreja (Mt 16.1320), "Jesus faz uma pergunta bem central: 'E vocês? [...] Quem vocês dizem quem eu sou?'." (COLE, 2007, p. 30). Assim ele finaliza:

Tudo sobre a igreja começa e termina com uma pergunta simples: Quem é Jesus para você? [...] Mesmo que acertemos todo o resto mas pulemos essa pergunta importante, não seremos verdadeiramente igreja. A igreja começa com Jesus: quem ele é e o que tem feito. (COLE, 2007, p. 31).

A segunda mudança que visa uma igreja mais relevante no contexto de Witmarsum, novamente exige um menor valor agregado à instituição, para, agora valorizar mais a parte relacional com outras pessoas.

\subsection{CRIANDO UMA CULTURA DE IDENTIFICAÇÃO E ACEITAÇÃO EM MEIO A UMA SOCIEDADE EXCLUDENTE}

No tópico 3.2 foi observada a presença de exclusão social na comunidade de Witmarsum. A igreja, para se tornar relevante, precisa identificar-se com essas pessoas rejeitadas. No mesmo sentido, Burke defende que a tarefa mais importante que os líderes podem empreender para cativar a sociedade pós-cristã é criar uma cultura saudável do tipo "venha, como você está”. Ele alerta que 
Frequentemente, líderes implementam novos cultos "para visitantes" ou cultos "pósmodernos" com música suave, velas, arte [...] ou qualquer coisa que a última conferência tenha lançado no mercado, mas deixam de lado os nutrientes mais essenciais para um crescimento saudável do corpo (BURKE, 2006, p. 27-28).

Perdue observa que "infelizmente, nas igrejas de hoje, é fácil ouvir o convite e entrar num sistema de crenças, em lugar de um relacionamento"(PERDUE, 2009, p. 31). Para Burke “a aceitação é a ação indireta mais palpável da graça. É atrair alguém para um relacionamento sem condenação” (BURKE, 2006, p. 113). Kimball relata esse desejo em Duggan:

Se eu fosse a uma igreja, gostaria que fosse como uma família. Uma família saudável em que todos prestam atenção uns aos outros [...]. Um lugar onde amam você, mesmo quando você não está agindo bem. $\mathrm{O}$ amor não deve ser condicional [...] acho que a igreja deve ser amorosa desse jeito (apud KIMBALL, 2011, p. 228).

MacDonald crê que "o mundo pode fazer quase tudo tão bem ou melhor do que igreja. Não é preciso ser cristão para construir casas, alimentar o faminto ou curar os enfermos. Há apenas uma coisa que o mundo não pode fazer. Ele não pode oferecer graça” (apud BURKE, 2006, p. 111).

Por um longo período era praxe na colônia Witmarsum, quando jovens alcançavam a idade certa para poderem frequentar o grupo de jovens, os rapazes mais antigos do grupo, recebiam estes jovens, muitas vezes ainda inseguros, fazendo brincadeiras de mau gosto com eles, como, por exemplo, forçando estes a subir num mastro ou numa árvore e "cantar de Galo". Os que assistiam esta apresentação achavam graça e se divertiam com isso. Quem presenciava estas cenas com frequência se deparou com cenas de revolta, decepção ou até desistência de continuar frequentando o grupo de jovens. Carlinhos relatou: "Quando eu entrei na 'Turma do Fervo' [grupo da bagunça, bebedeira, etc.] fui recebido com alegria [...] e no grupo de jovens da igreja 'pularam na minha goela'".

Burke ratifica que "muitas pessoas não acreditarão que Deus as aceitará e amará até que aqueles que alegam conhecê-lo comecem a mostrar-lhes.”. As novas gerações, segundo ele, não aderirão ao culto "se não experimentarem um autêntico apoio relacional" (BURKE, 2006, p. 59, 114).

Baumann crê que "o tema central na Palavra de Deus é a vida em comunidade. O verdadeiro discípulo só pode crescer e encontrar realização entre pessoas” (BAUMANN, 2009, p. 2). Cole recorda que, "quando o Novo Testamento usa um prédio como uma metáfora da Igreja, ele rapidamente acrescenta que é feito de pedras vivas (1Pe 2.5)" (COLE, 2007, p. 63).

Conclui-se assim que, numa sociedade excludente, o desafio para a igreja relevante é ser uma igreja de aceitação e comunitária. Dyck lembra que "a vida em comunidade é algo 
característico no meio Menonita. Eles têm praticado este modo de vida desde os tempos dos anabatistas. A vida comunitária era um fator de sobrevivência na sua jornada de quatro séculos" (DYCK, 1992, p. 416). Pauls entende que "a Igreja nos séc. XVI e XVII cresceu e se expandiu através da família" (PAULS, 2011, p. 233). Ou seja, o desafio da igreja de Witmarsum é retornar as raízes características dos Menonitas.

\subsection{CRIANDO UMA CULTURA DE CONTENTAMENTO E AJUDA AO PRÓXIMO EM MEIO A UMA SOCIEDADE DE CONSUMO}

Ricardo relata que, com o falecimento de seu irmão, ele ficou perdido, pois, até então as questões bancárias eram de responsabilidade deste, enquanto Ricardo, por sua vez, cuidava da parte braçal. Sem seu irmão, ele precisava de apoio. Por ter ficado com muitas dívidas, ele necessitava de terras para plantar: "O que me incomodou muito, foi quando um proprietário maior do que eu [membro de igreja], ganhou o direito de continuar o plantio numa área que eu precisava para o plantio [...]. Perdi o direito de plantar naquela área!”.

Com o depoimento do Ricardo vem a constatação de que a ganância pode ferir e destruir relacionamentos também em Witmarsum. Nesta comunidade se percebe que alguns deslancharam financeiramente e outros menos. Como as terras para o plantio tornam-se cada vez mais escassas e o preço do aluguel e da compra são altíssimos, pequenos agricultores têm encontrado grande dificuldade para o plantio. Agricultores mais fortes compram ou alugam as áreas para o plantio e com isso os agricultores de pequeno porte, às vezes, não conseguem terras suficientes para o plantio.

Junto a essa apuração, surge a pergunta: “Como pensar na comunidade da fé como caminho de comunhão, adoração, serviço e solidariedade em meio a uma cultura de consumo?" (BOMILCAR, 2012, p. 133). O próprio Bomilcar crê que:

podemos pegar uma via repleta de muita vida quando nos colocarmos de maneira sábia [...] em uma sociedade que [...] tenta consumir e adquirir e que gera sequelas na vida das pessoas, além de sofrimento também. Temos um evangelho que pode balizar, através de nós, o compromisso da solidariedade[...] de uma maneira mais amorosa e doadora. O amor de Cristo em nós se formos saudavelmente comunidade da fé, pode trazer vida para muitos e transformar realidades. (BOMILCAR, 2012, p. 142).

Em Witmarsum, Marcelo, pecuarista, relata que poucos são generosos, mas recentemente teve uma experiência positiva com seus vizinhos cristãos: foram eles que lhe auxiliaram a fazer silagem. Sua máquina tinha estragado, o que o levou ao desespero. Quando 
solicitou auxílio ao seu vizinho cristão, este dedicou todo o seu tempo no reparo da máquina. A reação de Marcelo, ao terminar a silagem foi de solicitar a sua esposa que agradecesse, via redes sociais, a todos os seus vizinhos que lhe auxiliaram na silagem, sendo que ainda pretende fazer um churrasco com eles.

Se por um lado, apurou-se que a ganância pode ferir e destruir relacionamentos, por outro também é possível verificar que, mesmo na questão agrícola há uma grande oportunidade para membros de igreja terem condutas exemplares, que permitem a construção de amizades duradouras junto aos menos favorecidos desta comunidade. Além de constatar isso na entrevista do Marcelo, também se percebe isso numa atitude do passado: quando um pecuarista/ agricultor não ia bem com a sua chácara ou estava afundado em dívidas, a comunidade oferecia um conselheiro para esta pessoa que estava em dificuldades, designado pela Cooperativa ou até alguém do rol de membros da igreja, que tivesse o dom, a capacidade nesta área. Este conselheiro tinha a incumbência de aconselhar, ajudar nas decisões tanto administrativas como também bem práticas, como, por exemplo, orientar a época de plantio, escolha das sementes, adubos, financiamentos, etc.

Retornando ao relato do Ricardo: Como seria bom, se alguém da igreja se prontificasse a se colocar ao lado deste jovem agricultor, auxiliando-o nas questões bancárias, parcelamento das dívidas, dando orientações de como e onde arrendar terras, etc.? Houve um caso em que um pecuarista (produtor de leite), sabendo da dificuldade financeira de outro produtor vizinho seu, "simplesmente" deu uma novilha para ele. São exemplos de amor e misericórdia que podem fazer uma enorme diferença no relacionamento entre membros de igreja e desigrejados.

\subsection{CRIANDO UMA CULTURA DE AUTENTICIDADE.}

O fato das pessoas da Colônia Witmarsum se conhecerem tão bem, as leva muitas vezes a carregar máscaras para poderem sobreviver em meio a este contexto. Ou seja, ser sincero e verdadeiro se torna um desafio! É comum refletir no que os outros vão pensar sobre uma atitude pessoal. Eduardo relata que em Witmarsum torna-se necessário fingir, "para não cair na boca do povo". Yancey denomina essa atitude de hipocrisia (YANCEY, 1997, p. 213). Quando entrevistado, Carlinhos admite que se sente sondado, despido, colocando máscaras. Este estilo de vida reside em muitos em Witmarsum. É muito difícil ou desafiador ser honesto num lugar fechado como este. Burke afirma que se a vida do líder e dos membros for transparente, isso contagiará outros (BURKE, 2006, p. 95). Segundo ele, a autenticidade: 
[...] começa comigo [...] quanto mais eu ando com Cristo, mais eu vejo o fariseu que existe em mim. Estou convencido de que o trabalho mais importante da liderança espiritual é ter uma vida espiritualmente autêntica. Mas, para isso, preciso vencer o engano de que, de alguma forma, sou melhor do que os outros (BURKE, 2006, p. 91).

Kimball nota que "muitos líderes céticos acreditam que as gerações emergentes têm impressões negativas sobre os cristãos e a igreja porque a cruz é uma pedra de tropeço.” E complementa afirmando que "o problema não é que elas tropeçam na cruz. O problema é que elas tropeçam nas atitudes de alguns cristãos [...] antes mesmo que consigam chegar à cruz" (KIMBALL, 2007, p. 234).

A igreja na comunidade de Witmarsum pode ser mais relevante, se ela incentivar os seus membros a levar uma vida em autenticidade: Segundo Felipe, "Não importa se o cara vem para a igreja ou não, a nossa amizade permanece" .

Conversando com uma pessoa que já pertenceu ao grupo desigrejado nesta comunidade, nota-se de como eles gostariam, que as pessoas da igreja expressassem um interesse mais genuíno, mais sincero por eles. Carlinhos, ex-morador de Witmarsum, disse: "Mostre interesse pela pessoa. Sem segundas intenções. Incondicionalmente. Esqueça a sua Igreja!" No mesmo sentido, Kimball observa que "é no âmbito dos relacionamentos e amizades sinceras com cristãos missionais que este público vai começar a ir nos cultos" (KIMBALL 2011, p. 239). Também cogita que pode ser por causa do pouco envolvimento da liderança eclesiástica com desigrejados, que motiva estes a formarem estereótipos sobre o público da igreja (KIMBALL, 2011, p. 36).

Vivemos hoje numa sociedade fragmentada e carente de relacionamentos saudáveis. As pessoas mudam-se, trocam de emprego, divorciam-se, fazem horas extras no trabalho todos os dias [...] gastam o tempo livre assistindo a alguns entre 1.700 canais de TV a cabo e navegando por milhões de sites na Internet, sacrificando seus relacionamentos. [...] temos uma geração dolorosamente só (BURKE, 2006, p. 58).

Apesar de viver num mundo globalizado, os relacionamentos estão em baixa. As redes sociais facilitam a vida e a comunicação das pessoas como nunca, mas, por outro lado, as pessoas nunca se sentiram tão sozinhas como nos tempos atuais. Será que em meio a tudo isso a Igreja ainda pode cumprir o seu papel? Ela pode ser relevante?

Burke afirma: "Temos uma enorme oportunidade para ensinar às pessoas como viver relacionamentos que curam e revigoram. Ninguém mais na sociedade pode suprir melhor essa necessidade (BURKE, 2006, p. 59). Cole lembra que "o primeiro lugar de habitação que Deus projetou para si mesmo era uma casa móvel [um tabernáculo], porque queria caminhar com o seu povo" (COLE, 2007, p. 64). Assim cabe também aos cristãos da comunidade de Witmarsum 
caminhar com o povo, deixando mais de lado os prédios para ser um bom referencial para os de fora da igreja.

Em 1João 1.8 lê-se: "Se afirmarmos que estamos sem pecado, enganamos a nós mesmos". Conversando com os desigrejados da Colônia de Witmarsum percebe-se a expectativa de ver a liderança eclesiástica atuando em resolução de conflitos. Frequentemente os desigrejados estão diretamente envolvidos em questões conflitantes e há pouca disposição para resolver estas questões. Há um anseio também por parte dos desigrejados por uma igreja que vai atrás de questões abertas, tentando assim resolver e restaurar relacionamentos, etc.

A falta de resolução de conflitos, inclusive é um dos motivos para o aumento do número de desigrejados. Bomilcar nota que eles vão se afastando cada vez mais do contexto comunitário e também do contexto da igreja, porém claramente anseiam por discutir as coisas abertamente, com muita sinceridade (BOMILCAR, 2012, p. 155). Também foi perceptível nas entrevistas que este público quer ser ouvido, ser levado a sério.

O que pessoas têm ouvido ou percebido no convívio com os cristãos em Witmarsum? Graça, humildade ou orgulho? É necessário que tanto líderes, como também membros eclesiásticos sejam ensinados a ser mais sensíveis e mais humanos nos seus relacionamentos diários. É necessário que dos púlpitos, nos estudos, através da liderança seja ensinado um Jesus mais humano e não somente divino. Bomilcar sugere "às pessoas que estão à procura de uma comunidade da fé que busquem encontrar uma liderança mais humana e sensível" (BOMILCAR, 2012, p. 103).

Felipe, em sua entrevista, observa: "Você se torna membro e por algum motivo você se afastou. O que acontece? Uma parte dos membros se afastam de você. Você não é bem-visto aqui. Eles se acham superiores em relação a você”. Para Bomilcar há nos cristãos a falta do reconhecimento da necessidade do arrependimento de pecados, da carência "de cura, de uma conversão de uma conversão genuína, de uma profunda renovação de nossa mente" (BOMILCAR, 2012, p. 102).

O Mestre Jesus tornou-se acessível para com aqueles que eram marginalizados pela sociedade. McKnight observa que nem

A própria família de Jesus não conseguia lidar com essa situação, vendo Jesus comungando não com pessoas "perfeitas", e sim com a "ralé" daquela época. Como é bonita a imagem de Jesus no meio de um círculo com amigos, familiares e, com certeza, pessoas que estavam à procura de serem compreendidos, que buscavam uma religião (MCKNIGHT, 2008, p. 72).

Seguindo o raciocínio de McKnight, pode-se afirmar que pessoas que se consideram seguidoras de Jesus devem tornar-se acessíveis para com aqueles que vivem à margem da 
sociedade eclesiástica. Eduardo comenta: "Vejo que muitos cristãos agem como o fariseu na Bíblia (Mt 18) [...] Esta atitude aflora aqui em Witmarsum [...] Entre os Menonitas é pregado muito a moral. Um moralista não pode ser uma boa pessoa".

\section{CONSIDERAÇÕES FINAIS}

O objetivo deste trabalho foi realizar uma pesquisa de campo na Colônia Witmarsum para descobrir os motivos do afastamento dos desigrejados da instituição igreja e consequentemente oferecer formas desta se aproximar em relação àqueles.

Primeiramente foi fornecida uma breve explicação sobre o significado de desigrejados, constituindo, em forma geral, um grupo de pessoas que creem em Deus, mas não participam da instituição eclesiástica. Em sequência foram apresentados, brevemente, alguns aspectos históricos e característicos da Colônia Witmarsum: fundada pelos Menonitas que descendem diretamente do movimento de fé anabatista, mas que atualmente também são marcados por seus fortes valores étnicos.

Apresentada essa parte, partiu-se para a exposição de dados obtidos na pesquisa qualitativa. Ouvindo as ponderações dos desigrejados, percebe-se o clamor por acolhimento, de ser percebido e compreendido. Também a insatisfação com o comportamento dos membros da igreja, que demonstram um comportamento no domingo e outro durante a semana.

Silva afirma que

em alguns casos, a resistência às igrejas instituídas nasce no coração e mente destas
pessoas por consequência de uma experiência desagradável com alguém que se
afirmava [...] fiel frequentador de uma delas. A desonestidade na forma de tratar um
negócio, a não manutenção da palavra em um determinado acordo, baixa qualidade
de um serviço prestado ou mesmo um comportamento indevido [...] geraram o
preconceito a toda e qualquer pessoa que se afirme frequentadora de igreja (SILVA,
2007, p. 15).

No decorrer da pesquisa, percebe-se que o conceito de enxergar a igreja pode e deve mudar. Nesta pesquisa os autores pesquisados relatam a questão da ambiguidade da Igreja dizendo que a igreja é "uma comunidade que abençoa e fere, anima e desanima, acolhe exclui, acerta e erra, realiza e frustra [...] como uma comunidade de seres humanos, não de anjos infalíveis" (BOMILCAR, 2012, p. 31).

Através deste trabalho nota-se a necessidade de enxergar e viver "Igreja" com mais realismo, não esperando que dentro da igreja não haverá decepção, feridas, etc. Muito pelo 
contrário, é na igreja que se encontram os feridos de alma, os doentes, onde há ofensas, mas onde também há cura de alma, restauração e consolo.

O grande desafio, tanto para os desigrejados - pessoas que se afastaram da vida da igreja, porque em algum momento foram feridos, decepcionados ou vivenciaram outro problema qualquer - como para os que frequentam a instituição igreja, é perdoar a igreja.

Ou seja, é necessário encontrar um equilíbrio: enxergar a igreja como um ajuntamento de pessoas pecadoras, que erram de vez em quando, sem isentar a igreja de sua responsabilidade de ser sal e luz no meio no qual ela está inserida.

Cabe à liderança desta comunidade ensinar e principalmente viver, apesar de todas as falhas e rusgas o princípio de "ser" igreja. Cabe a eles viver e ensinar um Jesus mais humano, mais "gente" nas mensagens dominicais, como também em grupos pequenos. Um Jesus que se doa a um mundo pecador e vive (habita) e se identifica com eles.

\section{REFERÊNCIAS BIBLIOGRÁFICAS}

BARKER, Kenneth (Org.). Bíblia de Estudo NVI. São Paulo: Vida, 2003.

BOMILCAR, Nelson. Os sem-igreja: buscando caminhos de esperança na experiência comunitária. São Paulo: Mundo Cristão, 2012.

BURKE, John. Proibida a entrada de pessoas perfeitas: um chamado à tolerância na igreja. São Paulo: Vida Acadêmica, 2006.

CAIRNS, Earle Edwin. O cristianismo através dos séculos: uma história da igreja cristã. 3. ed. São Paulo: Vida Nova, 2008.

CARSON, D. A. O comentário de Mateus. São Paulo: Shedd, 2010.

CÉSAR, M. C. Feridos em nome de Deus. São Paulo: Mundo Cristão, 2009.

CHAMPLIN, Russel Norman. O Novo Testamento interpretado versículo por versículo.

São Paulo: Hagnos, 2002. 6 v.

COLE, Neil. Igreja Orgânica: Plantando a fé onde a vida acontece. Rio de Janeiro: Habacuc, 2007

DYCK, Cornelius J. Uma Introdução à história Menonita: uma história popular dos anabatistas e dos Menonitas. Campinas: Cristã Unida, 1992.

FERREIRA, Yoshiya Nakagawara. Imigrantes: progresso material e diversidade cultural no Paraná. Revista Geografia, Londrina, v. 5, 1988, p. 100-109.

GEORGE, Timothy. Teologia dos reformadores. São Paulo: Vida Nova, 1994.

HOLM, Carla Caroline; CARDOZO, Poliana Fabíula. Exploração do patrimônio étnico em Colônia Witmarsum: os menonitas e suas diversas migrações ao redor do mundo. Revista Contribuciones a las Ciencias Sociales, n. 27, jan. - mar., 2015. Disponível em: <http://www.eumed.net/rev/cccss/2015/01/witmarsum.html >. Acesso em: 10/10/2015 
JACOB, C. R. et. al. Atlas da filiação religiosa e indicadores sociais no Brasil. Rio de Janeiro: PUC - Rio; São Paulo, Loyola, 2003, p. 115

JACOBSEN Wayne; COLEMAN Dave. Por que você não quer mais ir à Igreja? Uma história sobre o verdadeiro sentido do amor de Deus. Rio de Janeiro: Sextante, 2009.

JANZEN, Harry. Por que os menonitas são como são? Fé, sociedade e cultura. In: SIEMENS, J. Udo (org.). Quem somos? 1930-2010: a saga menonita: rompendo a barreira cultural. Curitiba: Esperança, 2010, p. 109-120.

KIMBALL, Dan. Eles gostam de Jesus mas não da igreja: insights das gerações emergentes sobre a igreja. São Paulo: Vida, 2011.

MARSHALL, I. H. Igreja I: Evangelhos. In: REID, Daniel G. (Ed.). Dicionário Teológico do Novo Testamento. São Paulo: Vida Nova, 2012, p. 635-639.

McGRATH, Alister E. Teologia histórica: uma introdução à história do pensamento cristão. São Paulo: Cultura Cristã. 2007.

McKNIGHT, Scot. 40 dias vivendo O Credo de Jesus. Curitiba: Esperança, 2008.

MUZIO, Rubens. O DNA da igreja: Comunidades cristãs transformando a nação. Curitiba: Esperança, 2010

O’BRIEN, P. T. Igreja II: Paulo. In: REID, Daniel G. (Ed.). Dicionário teológico do Novo Testamento. São Paulo: Vida Nova, 2012, p. 639-648.

PAULS, Alfred. Menonita, conte sua história. In: SIEMENS, J. Udo (org.). Quem somos? 1930-2010: a saga menonita: rompendo a barreira cultural. Curitiba: Esperança, 2010, p. 2156.

Menonitas alemães no Paraná. In: VITECK, Harto (org.). Imigração alemã no Paraná: 180 anos - 1829-2009. Marechal Cândido Rondon: Germânica, 2011, p. 197-233.

. Witmarsum para conhecer e gostar. In: SIEMENS, J. Udo (org.). Quem somos? 19302010: a saga menonita: rompendo a barreira cultural. Curitiba: Esperança, 2010, p. 155-166.

PAULS JR., Peter. “MENNONITEN IN BRASILIEN". GEDENKSCHRIFT zum 50 Jahr - Jubiläum ihrer Einwanderung 1930 1980. (Documento histórico para o jubileu dos 50 anos de imigração menonita no Brasil). Witmarsum: 1980.

Witmarsum in Paraná. Witmarsum: s/ Editora, 1976.

PERDUE, Bob. Dez escolhas de vida: recuperando a vida que você sempre quis viver. São Bento do Sul: União Cristã, 2009.

SHELLEY, Bruce L. História do cristianismo: Ao Alcance de Todos. São Paulo: Shedd, 2004.

SILVA, Ricardo Agreste da. Igreja? Tô fora!. São Paulo: SOCEP, 2007.

YANCEY, Philip. Maravilhosa graça. 4. ed. São Paulo: Vida. 1997. 